\title{
Implementation Research to Advance the Global HIV Response: Introduction to the JAIDS Supplement
}

Elvin Geng ${ }^{1} \mathrm{MD}, \mathrm{MPH}$, James Hargreaves ${ }^{2} \mathrm{PhD}$, Maya Peterson ${ }^{3} \mathrm{MD}, \mathrm{PhD}$, Stefan Baral ${ }^{4} \mathrm{MD}$, $\mathrm{MPH}, \mathrm{MBA}$

1 Division of Infectious Diseases in the Department of Medicine and the Center for Dissemination and Implementation Science at the Institute for Public Health, Washington University School of Medicine in St. Louis, St. Louis, MO, USA

2 Faculty of Public Health and Policy, London School of Hygiene and Tropical Medicine, London, UK

3 Division of Epidemiology and Biostatistics, School of Public Health, University of California, Berkeley, Berkeley, CA, USA

4 Department of Epidemiology, Johns Hopkins School of Public Health, Baltimore, MD, USA

\section{Corresponding author:}

Elvin Geng, Email elvin.geng@wustl.edu

Washington University School of Medicine in St. Louis 4990 Children's Place

St. Louis, MO 63110

Conflict of interest: None 
The scientific response to the HIV pandemic has reached a moment of great promise, but also of renewed urgency. Over the last 30 years, basic and clinical sciences have produced an armamentarium of highly potent medications and other interventions to treat and prevent HIV infection. When used consistently, antiretroviral therapy can restore a near-normal lifespan for persons living with $\mathrm{HIV}^{[1]}$ and prevent transmission in persons exposed to HIV ${ }^{[2]}$. Yet today, only around half of persons living with HIV have been tested, accessed treatment and achieved viral suppression $^{[3]}$. Moreover, pre-exposure prophylaxis, medical male circumcision and condoms are used only by a fraction of those who could benefit. Even with robust global and domestic investments to address the HIV pandemic, we have not been able to realize the full promise offered by these tools to reduce HIV incidence and mortality. As a result, HIV remains a potent public health threat globally, and continues to demand urgent prioritization.

Failure to achieve maximum public health impact with the efficacious interventions available is not, however, unique to the field of HIV. Americans receive approximately $50 \%$ of indicated care across a spectrum of conditions; globally this figure is far lower, even when costs are not prohibitive ${ }^{[4]}$. Awareness of this alarming chasm has motivated the development and growth of the field of implementation research (IR). IR strives to achieve scientific objectives shared by all fields: creating generalizable, transparent, public and rigorous knowledge. IR, however, also emphasizes key and distinctive perspectives and has introduced substantive innovations to address implementation problems. IR, for example, seeks not just the right answer, but also the right questions through stakeholder engagement and participatory research; considers public health impact in the appraisal of science (e.g., the REAIM ${ }^{[5]}$ ); attempts to find optimal balance between external as well as internal validity; offers novel frameworks to organize the dizzying complexity of drivers of implementation (e.g., Consolidated Framework for Implementation Research $\left.{ }^{[6]}\right)$; incorporates theories to explain behaviour of systems and people (e.g., normalisation process theory ${ }^{[7]}$ ); specifies reporting requirements in implementation research (e.g., STARI ${ }^{[8]}$ ); proposes novel study designs (e.g., hybrid designs ${ }^{[9]}$ ) and has created new streams of discourse (e.g., the journal Implementation Science and dedicated scientific meetings).

The encounter between the scientific response to HIV and the rapidly growing field of implementation research creates a unique opportunity - but one that we must collectively and urgently exploit. The HIV field has a long-standing and successful research agenda to understand behaviors associated with HIV acquisition and transmission as well as a robust literature on health behaviours. Perspectives from implementation research, however, can enrich and accelerate progress made to date - both by linking to similar challenges in other health fields as well as through original perspectives. Yet, while the HIV research community broadly recognizes that gaps in implementation stand in the way of greater public health progress, neither full commitment to implementation science nor consensus about the field's foundational perspectives are firmly established. Some, who don't doubt the importance of implementation nor the power of science, remain sceptical of a "science of implementation" and the contextual and behavioural inquiry implied. Others who recognize the need for a "science of implementation" in the HIV response may find the emphasis on interdisciplinary, stakeholder-engaged processes, use of implementation theories and frameworks, importance of external validity, and the value of fit and reach with health systems unconvincing. To be most effective, both a strong cadre of individuals carrying out implementation research, as well as a community that scientifically supports, elevates and invests in this area is needed. 
In September of 2018, we issued an open call as well as invited submissions on HIV-related implementation research with attention to featuring methodological innovations. The resulting collection offers a window into the leading edge of HIV implementation science today and, we hope, will also help propel our collective engagement with IR forward.

One set of papers in this supplement presents perspectives on the HIV response from traditions in the social sciences, with the promise of catalyzing deeper cross-disciplinary dialogue. Theories and frameworks such as the Consolidated Framework for Implementation Research which are widely used in IR draw from a range of underlying disciplines and traditions, and this series of papers highlights those perspectives. Jacob Bor and Harsha Thirumurthy, both economists, observe that humans are not health maximisers, but rather utility (or happiness) maximisers - a central tenant of economics - and explores implications of this observation on research addressing the HIV epidemic. Highlighting methods used in marketing, Alexandra Minnis and colleagues describe the use of discrete choice experiments to quantify preferences of women for different attributes of female-controlled HIV prevention products, which can inform designs which facilitate adoption and sustained use. An anthropologist by training, Norma Ware uses ethnography to offer novel conceptualizations about how health care workers and patients experience the implementation of evidence-based HIV services - thus opening the door to innovations in service delivery. Using work from Zambia, Laura Beres and colleagues review human centred design - in which researchers and end-users co-create knowledge - to enhance the uptake of innovations for HIV treatment and prevention. Guy Harling and colleagues explores sociological perspectives and tools used to understand the HIV response, with an emphasis on social networks. Citing work in China, Dan Wu and colleagues summarize the utility of crowd sourcing to better meet the sexual health needs of underserved populations. Finally, Anjuli Wagner and colleagues draws from systems engineering to describe a package of activities that systematically identify service delivery gaps. Overall, we hope these papers will act as "gateway" for further dialogue between investigators working on HIV and diverse disciplinary traditions.

Another set of papers in this volume offer theoretical or practical guidance for the conduct of implementation research addressing HIV. Megha Mehrotra and colleagues formalize the ofteninvoked concept of context - using differentiated service delivery models as an example -- through applying Pearl and Bareinboim's transport framework, thus linking a conceptual understanding of "context" with epidemiolocal tools to address context. James Hargreaves and colleagues address five critical challenges to trials asking implementation questions. Several papers describe methods or approaches for conduct of IR with vulnerable and under-reached populations. Christian Grov and colleagues describe internet-only cohorts to reach and follow MSM that would otherwise may not participate in research. Sheree Schwartz and colleagues use the Consolidated Framework for Implementation Research (CFIR) to assess research in key populations that require cognizance of stigma, criminalization and other forms of discrimination. Joshua Solomon presents a novel approach, called comparative strategy, to advance the use of data on costs into IR. Jennifer Stewart and colleagues have led cutting edge work with the faith-based community to address HIV prevention for African American women, and in this supplement, they lay out best practices in public health and IR with religious leaders to best leverage a crucial and underused source of social influence. Laura Packel and colleagues present a series of studies that trace the evolution of research agenda around incentives for engagement in HIV care from efficacy to effectiveness and to implementation. This set of papers provide a map for new pathways in the conduct of IR in the HIV response.

Finally, a number of submissions describe real-world implementation of activities to address the HIV epidemic thorough the lens of implementation research, which represent case studies "learning while doing." Susan Buchbinder and Diane Havlir describe San Francisco's multisector 
HIV response based on the collective impact theory that has driven HIV incidence and mortality to historical lows. Maira Sohail and colleagues outline the formation of a network of health care facilities in Alabama to engage in both quality improvement and research activities - illustrating the creation of a practice-based research platform that promises to generate data highly relevant to routine practice settings in the US South. Geri Donenberg and colleagues from Rwanda describe implementing and evaluating HIV services for adolescents using the EPIS framework and demonstrate how application of a framework from IR can strengthen evaluation. From Washington State, Julia Dombrowski, who holds positions in both a service delivery agency as well as in academia, argue that that the involvement of public health agencies as producers as well as consumers of IR can elevates the relevance and rigor of research. Industry, an important partner in the HIV response, is rarely included in the implementation dialogue. D Allen Roberts and colleagues examine cost and cost effectiveness of innovative models of HIV service delivery. Here, Maggie Czarnogorski contributes a perspective from ViiV and articulates the role that ViiV can play in promoting IR, especially at this moment in order to make the most of long-acting injectable medications which are on the cusp of reaching market. Delivette Castor led investments in IR from the United States Agency for International Development (USAID) and the President's Emergency Plan for AIDS Relief (PEPFAR), and with colleagues in this supplement, offers an appraisal of the public health impacts of research investments.

As Robert Eisinger, Carl Dieffenbach and Anthony Fauci describe in the opening piece of the supplement, the scientific response to HIV has made a remarkable journey to date, but one that we must complete through implementation research. Approximately 30 years ago, AIDS was a little understood and greatly feared mystery illness. Today, we have a detailed molecular understanding of the HIV virus and its pathophysiology. We have dozens of medications and other interventions to treat and prevent HIV, all tested through rigorous studies. We have a robust understanding of the economic, social and psychological drivers of the epidemic. Given these successes, tomorrow's critical scientific questions naturally turn to addressing implementation. To do so effectively, the research community must pivot to strengthen the skills, teams and tools needed to carry out research on the behaviour of systems, organizations, health care workers, as well as patients and communities. We hope this collection offers a window onto both the current practice of IR as well as future aspirations to reach the destination of bringing this pandemic to a close.

\section{$\underline{\text { References: }}$}

1. Helleberg M, Afzal S, Kronborg G, Larsen CS, Pedersen G, Pedersen C, et al. Mortality attributable to smoking among HIV-1-infected individuals: a nationwide, population-based cohort study. Clinical Infectious Diseases 2012; 56(5):727-734.

2. Cohen MS, Chen YQ, McCauley M, Gamble T, Hosseinipour MC, Kumarasamy N, et al. Prevention of HIV-1 infection with early antiretroviral therapy. New England journal of medicine 2011; 365(6):493505.

3. Granich R, Gupta S, Hall I, Aberle-Grasse J, Hader S, Mermin J. Status and methodology of publicly available national HIV care continua and 90-90-90 targets: a systematic review. PLoS medicine 2017; 14(4):e1002253.

4. McGlynn EA, Asch SM, Adams J, Keesey J, Hicks J, DeCristofaro A, et al. The quality of health care delivered to adults in the United States. New England journal of medicine 2003; 348(26):2635-2645. 5. Glasgow RE, Vogt TM, Boles SM. Evaluating the public health impact of health promotion interventions: the RE-AIM framework. American journal of public health 1999; 89(9):1322-1327. 
6. Damschroder LJ, Aron DC, Keith RE, Kirsh SR, Alexander JA, Lowery JC. Fostering implementation of health services research findings into practice: a consolidated framework for advancing implementation science. Implementation science 2009; 4(1):50.

7. Murray E, Treweek S, Pope C, MacFarlane A, Ballini L, Dowrick C, et al. Normalisation process theory: a framework for developing, evaluating and implementing complex interventions. $B M C$ medicine 2010; 8(1):63.

8. Pinnock H, Barwick M, Carpenter CR, Eldridge S, Grandes G, Griffiths CJ, et al. Standards for reporting implementation studies (StaRI) statement. Bmj 2017; 356:i6795.

9. Curran GM, Bauer M, Mittman B, Pyne JM, Stetler C. Effectiveness-implementation hybrid designs: combining elements of clinical effectiveness and implementation research to enhance public health impact. Medical care 2012; 50(3):217.

1. Helleberg M, Afzal S, Kronborg G, Larsen CS, Pedersen G, Pedersen C, et al. Mortality attributable to smoking among HIV-1-infected individuals: a nationwide, population-based cohort study. Clinical Infectious Diseases 2012; 56(5):727-734.

2. Cohen MS, Chen YQ, McCauley M, Gamble T, Hosseinipour MC, Kumarasamy N, et al. Prevention of HIV-1 infection with early antiretroviral therapy. New England journal of medicine 2011; 365(6):493505.

3. Granich R, Gupta S, Hall I, Aberle-Grasse J, Hader S, Mermin J. Status and methodology of publicly available national HIV care continua and 90-90-90 targets: a systematic review. PLoS medicine 2017; 14(4):e1002253.

4. McGlynn EA, Asch SM, Adams J, Keesey J, Hicks J, DeCristofaro A, et al. The quality of health care delivered to adults in the United States. New England journal of medicine 2003; 348(26):2635-2645. 5. Glasgow RE, Vogt TM, Boles SM. Evaluating the public health impact of health promotion interventions: the RE-AIM framework. American journal of public health 1999; 89(9):1322-1327.

6. Damschroder L, Aron DC, Keith RE, Kirsh SR, Alexander JA, Lowery JC. Fostering implementation of health services research findings into practice: a consolidated framework for advancing implementation science. Implementation science 2009; 4(1):50.

7. Murray E, Treweek S, Pope C, MacFarlane A, Ballini L, Dowrick C, et al. Normalisation process theory: a framework for developing, evaluating and implementing complex interventions. $B M C$ medicine 2010; 8(1):63.

8. Curran GM, Bauer M, Mittman B, Pyne JM, Stetler C. Effectiveness-implementation hybrid designs: combining elements of clinical effectiveness and implementation research to enhance public health impact. Medical care 2012; 50(3):217.

1. Helleberg M, Afzal S, Kronborg G, Larsen CS, Pedersen G, Pedersen C, et al. Mortality attributable to smoking among HIV-1-infected individuals: a nationwide, population-based cohort study. Clinical Infectious Diseases 2012; 56(5):727-734.

2. Cohen MS, Chen YQ, McCauley M, Gamble T, Hosseinipour MC, Kumarasamy N, et al. Prevention of HIV-1 infection with early antiretroviral therapy. New England journal of medicine 2011; 365(6):493505.

3. Granich R, Gupta S, Hall I, Aberle-Grasse J, Hader S, Mermin J. Status and methodology of publicly available national HIV care continua and $\mathbf{9 0 - 9 0 - 9 0 ~ t a r g e t s : ~ a ~ s y s t e m a t i c ~ r e v i e w . ~ P L o S ~ m e d i c i n e ~ 2 0 1 7 ; ~}$ 14(4):e1002253.

4. McGlynn EA, Asch SM, Adams J, Keesey J, Hicks J, DeCristofaro A, et al. The quality of health care delivered to adults in the United States. New England journal of medicine 2003; 348(26):2635-2645. 5. Glasgow RE, Vogt TM, Boles SM. Evaluating the public health impact of health promotion interventions: the RE-AIM framework. American journal of public health 1999; 89(9):1322-1327. 
6. Damschroder $\amalg$, Aron DC, Keith RE, Kirsh SR, Alexander JA, Lowery JC. Fostering implementation of health services research findings into practice: a consolidated framework for advancing implementation science. Implementation science 2009; 4(1):50.

7. Curran GM, Bauer M, Mittman B, Pyne JM, Stetler C. Effectiveness-implementation hybrid designs: combining elements of clinical effectiveness and implementation research to enhance public health impact. Medical care 2012; 50(3):217.

1. Helleberg M, Afzal S, Kronborg G, Larsen CS, Pedersen G, Pedersen C, et al. Mortality attributable to smoking among HIV-1-infected individuals: a nationwide, population-based cohort study. Clinical Infectious Diseases 2012; 56(5):727-734.

2. Cohen MS, Chen YQ, McCauley M, Gamble T, Hosseinipour MC, Kumarasamy N, et al. Prevention of HIV-1 infection with early antiretroviral therapy. New England journal of medicine 2011; 365(6):493505.

3. Granich R, Gupta S, Hall I, Aberle-Grasse J, Hader S, Mermin J. Status and methodology of publicly available national HIV care continua and 90-90-90 targets: a systematic review. PLoS medicine 2017; 14(4):e1002253.

4. McGlynn EA, Asch SM, Adams J, Keesey J, Hicks J, DeCristofaro A, et al. The quality of health care delivered to adults in the United States. New England journal of medicine 2003; 348(26):2635-2645. 5. Damschroder L, Aron DC, Keith RE, Kirsh SR, Alexander JA, Lowery JC. Fostering implementation of health services research findings into practice: a consolidated framework for advancing implementation science. Implementation science 2009; 4(1):50.

6. Curran GM, Bauer M, Mittman B, Pyne JM, Stetler C. Effectiveness-implementation hybrid designs: combining elements of clinical effectiveness and implementation research to enhance public health impact. Medical care 2012; 50(3):217.

1. Helleberg M, Afzal S, Kronborg G, Larsen CS, Pedersen G, Pedersen C, et al. Mortality attributable to smoking among HIV-1-infected individuals: a nationwide, population-based cohort study. Clinical Infectious Diseases 2012; 56(5):727-734.

2. Cohen MS, Chen YQ, McCauley M, Gamble T, Hosseinipour MC, Kumarasamy N, et al. Prevention of HIV-1 infection with early antiretroviral therapy. New England journal of medicine 2011; 365(6):493505.

3. Granich R, Gupta S, Hall I, Aberle-Grasse J, Hader S, Mermin J. Status and methodology of publicly available national HIV care continua and $\mathbf{9 0 - 9 0 - 9 0 ~ t a r g e t s : ~ a ~ s y s t e m a t i c ~ r e v i e w . ~ P L o S ~ m e d i c i n e ~ 2 0 1 7 ; ~}$ 14(4):e1002253.

4. McGlynn EA, Asch SM, Adams J, Keesey J, Hicks J, DeCristofaro A, et al. The quality of health care delivered to adults in the United States. New England journal of medicine 2003; 348(26):2635-2645.

5. Curran GM, Bauer M, Mittman B, Pyne JM, Stetler C. Effectiveness-implementation hybrid designs: combining elements of clinical effectiveness and implementation research to enhance public health impact. Medical care 2012; 50(3):217.

1. Helleberg M, Afzal S, Kronborg G, Larsen CS, Pedersen G, Pedersen C, et al. Mortality attributable to smoking among HIV-1-infected individuals: a nationwide, population-based cohort study. Clinical Infectious Diseases 2012; 56(5):727-734.

2. Cohen MS, Chen YQ, McCauley M, Gamble T, Hosseinipour MC, Kumarasamy N, et al. Prevention of HIV-1 infection with early antiretroviral therapy. New England journal of medicine 2011; 365(6):493505.

3. Granich R, Gupta S, Hall I, Aberle-Grasse J, Hader S, Mermin J. Status and methodology of publicly available national HIV care continua and $\mathbf{9 0 - 9 0 - 9 0 ~ t a r g e t s : ~ a ~ s y s t e m a t i c ~ r e v i e w . ~ P L O S ~ m e d i c i n e ~ 2 0 1 7 ; ~}$ 14(4):e1002253.

4. McGlynn EA, Asch SM, Adams J, Keesey J, Hicks J, DeCristofaro A, et al. The quality of health care delivered to adults in the United States. New England journal of medicine 2003; 348(26):2635-2645. 
1. Helleberg M, Afzal S, Kronborg G, Larsen CS, Pedersen G, Pedersen C, et al. Mortality attributable to smoking among HIV-1-infected individuals: a nationwide, population-based cohort study. Clinical Infectious Diseases 2012; 56(5):727-734.

2. Cohen MS, Chen YQ, McCauley M, Gamble T, Hosseinipour MC, Kumarasamy N, et al. Prevention of HIV-1 infection with early antiretroviral therapy. New England journal of medicine 2011; 365(6):493505.

3. Granich R, Gupta S, Hall I, Aberle-Grasse J, Hader S, Mermin J. Status and methodology of publicly available national HIV care continua and $\mathbf{9 0 - 9 0 - 9 0 ~ t a r g e t s : ~ a ~ s y s t e m a t i c ~ r e v i e w . ~ P L o S ~ m e d i c i n e ~ 2 0 1 7 ; ~}$ 14(4):e1002253.

1. Helleberg M, Afzal S, Kronborg G, Larsen CS, Pedersen G, Pedersen C, et al. Mortality attributable to smoking among HIV-1-infected individuals: a nationwide, population-based cohort study. Clinical Infectious Diseases 2012; 56(5):727-734.

2. Cohen MS, Chen YQ, McCauley M, Gamble T, Hosseinipour MC, Kumarasamy N, et al. Prevention of HIV-1 infection with early antiretroviral therapy. New England journal of medicine $2011 ; 365(6): 493-$ 505.

1. Cohen MS, Chen YQ, McCauley M, Gamble T, Hosseinipour MC, Kumarasamy N, et al. Prevention of HIV-1 infection with early antiretroviral therapy. New England journal of medicine 2011; 365(6):493505. 